\title{
NOTAS PROVISÓRIAS SOBRE A ESTRATÉGIA DE DESENVOLVIMENTO E OS GRANDES PROJETOS DA AMAZÔNIA ${ }^{1}$
}

\author{
Benjamin Alvino de Mesquita \\ Universidade Federal do Maranhão (UFMA)
}

NOTAS PROVISÓRIAS SOBRE A ESTRATÉGIA DE DESENVOLVIMENTO E OS GRANDES PROJETOS DAAMAZÔNIA

Resumo $O$ roteiro discute a estratégia de desenvolvimento recente da Amazônia no contexto neoliberal, apontando as mudanças que ocorreram na região, onde a presença de grandes projetos constitui peça importante na compreensão desse cenário. No período atual, são os grandes projetos do PAC e de empresas globais que lideram esse processo. Em ambos, a marca registrada é o financiamento público, assim como o caráter predatório dos empreendimentos, o desrespeito à sociedade local e a ausência de uma proposta de desenvolvimento que atenda aos interesses da maioria. Sem dúvida, mudanças significativas se processam na Amazônia, sob todos os aspectos, mas as desigualdades, a exclusão social, a destruição da biodiversidade e, portanto, a concentração da riqueza, têm se agravado.

Palavras-chave: Estratégia de desenvolvimento, Amazônia, grandes projetos, desigualdades socioeconômicas.

\section{PROVISORY NOTES ABOUT THE DEVELOPMENT STRATEGY AND THE AMAZONIAN GREAT PROJECTS}

Abstract: The article discusses the recent development strategy of Amazon in the neoliberal context, pointing out the changes that have occurred in the region, where the presence of large projects is an important part in understanding this scenario. In the current period, the major projects of the PAC and global companies that lead this process. On both, the trademark is the public financing and the predatory nature of the projects, disrespect to the local society and the absence of a development proposal that meets the interests of most. Without doubt, meaningful changes are processed in the Amazon in all respects, but the inequalities, social exclusion, destruction of biodiversity and hence the concentration of wealth has worsened.

Keywords: Development strategy, Amazon, major projects, socioeconomic inequalities. 
Recebido em 25.11.2013 Aprovado em 06.01.2014 1 INTRODUÇAO

A estratégia de desenvolvimento $e$ os grandes projetos da Amazônia têm muito a ver com os acontecimentos recentes da sociedade civil, questionando os poderes constituídos, levantando e exigindo o equacionamento de antigas e importantes questões estruturais, nos planos político, social e econômico; mostram bem o grau de insatisfação vigente no país e também chamam a atenção para essa estratégia de desenvolvimento que o Estado Brasileiro insiste em efetivar, sem, no entanto, satisfazer as demandas crescentes e diferenciadas que se acumulam, há décadas, sem equacionamento algum. Voltou à pauta política e também econômica a prioridade (ninguém sabe para quem) dado a megainvestimentos - como estádios de futebol, cidades alojamentos e trem bala que, concretamente, não resolvem absolutamente nada em termos de demandas reprimidas mobilidade urbana, habitação, saúde, educação essenciais e indispensáveis a um mínimo de bemestar social, mas cumpre uma função importante na concentração e centralização do capital, que repercute desigualmente no acesso à riqueza.

Uma olhada no modelo de desenvolvimento econômico do país das últimas décadas permite constatar que essa prática prevalece desde o período da ditadura. Antes se dizia que essa opção decorria do regime autoritário da época, mas os fatos desmentem essa versão: a democracia ai está consolidada, mas a ênfase do modelo econômico baseado na grande empresa permanece e foi aperfeiçoada pelos antigos opositores da ditadura. Hoje, mais do que antes, a relação capital/ trabalho é desigual e desfavorável a este último; praticamente todos os setores da economia são dominados por cartéis, o que amplifica ainda mais a concentração e centralização de capital, em todos os setores econômicos; isto é, um número a cada dia menor de capitais controla a produção agrícola e industrial e o comércio. Como no passado, esse movimento do grande capital não dispensa o apoio fundamental do Estado, embora tenha um discurso liberal que negue esse conluio. Essa associação de interesses foi particularmente excepcional após a adoção de políticas neoliberais nos anos 1990, quando o Estado Brasileiro abdica de suas funções históricas de mentor e condutor de uma política de desenvolvimento proativa favorável à maioria, e se encolhe no âmbito da passividade de coordenação de interesses privados, que nem sempre representa o que a sociedade quer, mas que favoreceu grandemente essa minoria representada por grandes empreendimentos.

Esse quadro de invisibilidade assumido pelo Estado prevaleceu até o lançamento do Programa de Aceleração do Crescimento (PAC), independentemente de quem estivesse no poder, à direita ou à esquerda. Quer dizer, no período pósditadura, é a mão invisível do mercado - o capital - que dita as regras do tipo de desenvolvimento, se inclusivo ou exclusivo. Como nessa perspectiva, a ação do Estado quanto à direção e ritmo dos investimentos não lhe cabe, o mercado tem o livre arbítrio de escolha em termos de atividade, se produtiva ou especulativa; tipo de produto commodity ou industrial; se mercado externo ou interno, e de localização territorial - se no centro dinâmico do capital ou na sua periferia. Resultado: ao prevalecer a lógica do capital, o lucro fácil e rápido, não interessa onde e como se efetiva, o nível de desenvolvimento econômico do país foi modesto e as suas regiões periféricas - Norte e Nordeste continuam tão periféricas quanto antes.

No segundo governo Lula, com o lançamento do PAC, que embora seja saudado como uma espécie de Plano de Metas, não passa de um conjunto de intervenções na área de infraestrutura, visando oferecer economia de escala aos investimentos, voltada para o mercado externo, de qualquer forma a sua concepção traz de volta a presença do Estado planejando a ocupação do território e dando a direção (muitas vezes equivocada) e ritmo de como deverá ser efetivada. Os saudosistas veem isso como a volta do Estado interventor ou do capitalismo de Estado, como se houvesse no país ambiente e/ ou vontade política para tanto.

Como o montante de investimentos concentrado na geração e transmissão de energia, transporte e logística, petróleo e gás - para algumas economias regionais (Norte e Nordeste, principalmente) não é significativo; os efeitos em termos de desenvolvimento econômico deverão ser secundários, e, como tal, poderá ocorrer um aprofundamento maior do gap que hoje separa essas regiões da área dinâmica da economia brasileira.

Nesse cenário mais geral, apontado anteriormente, percebe-se que a locomotiva dos investimentos regionais é constituída essencialmente pelos projetos do PAC; uns diretamente realizados pelo Estado e empresas estatais, outros indiretamente, com a presença do financiamento público do BNDES, e outros ainda pelo capital privado, mas todos articulados à dinâmica internacional e tocados ao ritmo que esta determina. À frente desses investimentos estão o grande capital e o Estado nacional; os demais atores contam muito pouco, até porque são frequentemente escamoteados de qualquer decisão.

Contemporaneamente, continua-se a oferecer como alternativa ou estratégia de desenvolvimento esse modelo de desenvolvimento econômico herdado dos anos 1970, que tinha por base o grande capital, a economia de enclave, o vínculo com o mercado externo e a especialização, como o caminho fácil para sair do atraso, da pobreza e da exclusão social, e, portanto a solução para as desigualdades socioespaciais (locais e regionais), 
que só têm se acentuado nessa lógica do mercado dominado por esse tipo de empresas ligadas às atividades intensivas em exploração de recursos naturais (mineral e agrícola), vinculadas às cadeias globais de commodities. Embora o sucesso dessas empresas globais, relacionadas às exportações crescentes, em termos de volume, valor e divisas geradas, sirva de argumento para ampliação e apoio governamental de novos investimentos, esse crescimento particular/privado não necessariamente tem se traduzido em termos de um desenvolvimento socioeconômico favorável à economia local/ regional. Ao contrário, em muitos locais, o que se constata é um descolamento dessa dinâmica global e regional. A alta especialização e o crescimento das exportações de poucos produtos, que não agregam valor, gerados por enclaves, não evitaram uma desindustrialização da economia; favoreceram a concentração da terra e da renda pessoal; (re) organizaram o território em termos de acesso e controle, com conseqüências desastrosas para a produção de alimentos em nível local/regional, além de deixar um passivo socioambiental crescente a ser custeado por todos.

2 O ENTENDIMENTO DA QUESTÃO: o lugar dos enclaves

Considera-se que esses processos de diferenciação socioespacial que se percebe no tempo e no espaço, com o avanço das forças produtivas, refletem a ação das forças de mercado e do Estado, sob diferentes aspectos. Como essa dinâmica da economia regional passa necessariamente pelo controle desses atores citados - o Estado e as grandes empresas -, cuja intervenção no geral se desvincula de questões locais, só uma mudança no formato atual dessa estratégia de desenvolvimento pode alterar o produto final que se nota na atualidade.

Ora, já vimos o que essa estratégia convencional de crescimento econômico, baseada na ação do mercado, trouxe à economia regional nas últimas décadas. A insistência do governo atual em continuar com os mesmos elementos dinamizadores do passado, isto é, grandes projetos, cheira a embromação, já que os atores (o Estado e as grandes empresas) e o expectador (a população) são os mesmos. Que resultados temos da situação anterior, ou o que poderemos esperar dessa nova estratégia de desenvolvimento vendida atualmente e em vigor nos últimos 50 anos e que se aprofunda, na época neoliberal, e cujo produto foi um acentuado processo de expropriação - criador de desigualdades e responsável por profundas mudanças nas relações sociais e espaciais onde se viu instalada? Creio que um caminho para a compreensão do atual desenvolvimento de uma região está no acompanhamento da atuação da grande empresa, que é a forma mais apurada do capitalismo. Seu modus operandi, meios e instrumentos revelam a promiscuidade entre o político e o econômico, da qual emerge uma simbiose que alavanca o processo de acumulação, que resulta em dois produtos: a concentração da riqueza e o aumento da desigualdade.

O entendimento dessa questão é dado por inúmeros autores. Mas, achamos particularmente interessante e simples o que Marx e Braudel propõem: é o acompanhamento do movimento da parte que efetivamente conta no capitalismo, ou seja, o grande capital e sua articulação com o poder. Para explicar isso, Braudel parte da categoria de análise - sistema mundial/longos séculos. Para ele, o capitalismo pode ser visto como um edifício ou uma complexa estrutura formada por andares, estágios ou etapas que se interligam. Teríamos assim, segundo ele, uma primeira camada, formada por uma economia extremamente elementar autossuficiente, que ele denomina camada da vida material ou camada da não economia (nãocapitalista), onde o capitalismo crava suas raízes, mas nunca consegue realmente penetrar. Outra intermediária (acima daquela) seria a economia de mercado, com suas multicomunicações horizontais, entre diferentes mercados; e uma última, acima de todos, seria o antimercado, dominado pelo grande capital, que é a parte de maior interesse de Braudel, pois é a partir daqui que ele explica o modus operandi do capitalismo. Essa ideia também já era dada por Marx (1987), pois, para se reconhecer e/ou apreender os meandros do capitalismo, é preciso, segundo Marx, ultrapassar a soleira da porta e ir aos porões, para encontrar o grande capital e o poder (política), ou então subir ao andar de cima no edifício do capitalismo, onde predominam os grandes predadores (a grande empresa, oligopólios e monopólios). É nessa camada ou andar superior da economia, onde atuam os capitais que controlam parte importante do mercado, seja ele qual for, que se enxerga a dinâmica econômica e a economia e a política estão em permanente simbiose.

É, portanto, nesse sentido que podemos entender essa inserção das regiões periféricas no cenário nacional e internacional do capitalismo. Essa relação entre Estado e grandes projetos de investimento não é novidade na Amazônia; vem de longa data. No período colonial já estava lá a borracha, na República na Fordlândia, no Jarí, na Icomi (Grupo Antunes), na ZFM, na Sudam, no Carajás ou no PAC. A questão, então, é saber se esse modelo de crescimento econômico imposto, fundamentado em megaprojetos, voltado para a exportação de commodities, constituído de enclaves, foi ou é salutar para a população local.

\section{A DINÂMICA REGIONAL RECENTE E A ESTRUTURA PRODUTIVA}

Até a década de 1980, essa dinâmica regional esteve associada à agropecuária e ao extrativismo. 
Posteriormente, ruma para a área mineral, em decorrência da implantação do Projeto Grande Carajás, e, recentemente, para o agronegócio de grãos, eucalipto e dendê (MESQUITA, 2009) e infraestrutura. Do ponto de vista produtivo, os grandes projetos de investimento do Carajás, como a Vale, a Alumar, a Albrás e, na década atual, as empresas do complexo soja, eucalipto e na era do PAC, as obras de infraestrutura produtiva introduziram mudanças no perfil produtivo da economia, diferentemente do que se esperava. A razão, em parte, está em primeiro lugar no perfil de uma parte das empresas aqui instaladas (enclaves ou quase enclaves), e também na guinada em termos de articulação industrial e comercial, que deixa de ser interna para ser externa. A maior inserção internacional da região, ocasionada pela demanda chinesa, impulsionou as exportações regionais de commodities minerais e agrícolas em nível significativo, em termos de volume, valor exportado e geração de divisas, mas nem por isso suficiente para compensar os pífios resultados agregados (taxa de crescimento, renda per capita) à economia regional, isso porque, como a economia regional tem esse caráter de enclave, os efeitos positivos são apropriados externamente à região, seja no núcleo central da economia - Sudeste - ou no exterior local de venda das commodities.

Ou seja, o que aconteceu com a economia regional nesses 30 anos de grandes projetos? Deixamos de ser um mero exportador de eletrônico e produtos extrativos - madeira, voltado para o mercado interno, para nos transformar numa base exportadora de minério de ferro e alumina (pós1985 mercado externo) e mais recentemente acrescentamos a essa pauta a soja. Mas o fato é que tanto na fase pré-Carajás (antes de 1980), quanto nas fases Carajás (1980-1995) e pós-Carajás (neoliberal), continuamos exportando commodities! É importante lembrar que em todas as fases o Estado mantém, via agências e bancos estatais, gordos subsídios ao capital, como forma de atração e barateamento dos custos de implantação.

Na década de 1970, em decorrência de uma política de desenvolvimento regional, a integração comercial e produtiva da Amazônia avança e se consolida. Tal processo é aprofundado com os megainvestimentos da era Carajás (1980-1990) e do PAC (2007), o que acarretou importantes mudanças no perfil inter e intrarregional, mas, apesar disso, a Amazônia, laboratório dessa estratégia de ações, comungada entre Estado e grande capital, continua, do ponto de vista econômico, uma economia modesta e insignificante (equivalente à economia do Paraná) para os padrões que representa em termos de população, área territorial e recursos naturais; o seu PIB é apenas $5,3 \%$ do país, enquanto a renda per capita não chega a 3/4 da nacional.

Operfil da economia reflete a dicotomia nacional, entre um número minúsculo de grandes unidades produtivas responsáveis pelo valor da produção e um maiúsculo número de pequenas unidades produtivas com pouca expressão econômica. No primeiro grupo estão os grandes projetos, estruturas oligopólicas da indústria extrativa, dos monocultivos e da indústria manufatureira da ZFM, a parte capitalista, política e economicamente organizada e poderosa - é o segmento que dá as cartas e que recebe as benesses do Estado para se instalar e permanecer na região. No outro extremo, numerosa e desorganizada, sem poder algum de barganha, se encontra a economia pré-capitalista, a não-economia, formada de pequenas unidades individuais e familiares. E, no meio de ambas, uma camada intermediária formada por pequenas e médias empresas, onde prevalecem formas mistas de organização da produção que faz a ponte entre a grande empresa e o mercado consumidor (MESQUITA, 2009).

A chegada de inúmeros empreendimentos privados nacionais e estrangeiros nas diferentes áreas produtivas (indústria, serviço e agropecuária) e a implantação de infraestrutura produtiva, hidroelétricas, rodovias, ferrovias, hidrovias e portos, alterou nas últimas décadas a distribuição relativa das macroestruturas setoriais e, com ela, a dinâmica setorial.

Nestes últimos anos (1995-2009), o avanço relativo da indústria perde força, ficando em torno dos $20 \%$, a agricultura, depois de forte declínio, estaciona ao redor de $13 \%$, enquanto o setor serviços mantém-se quase inalterado no período $(67 / 68 \%)$. Mas, quando se observa a taxa de crescimento setorial em igual período, constata-se que a dinâmica foi dada pela indústria.

Por outro lado, verifica-se, também, que os investimentos mais recentes (2000-2009), período excepcional para as exportações de commodities, e, portanto, favorável à Amazônia e seus enclaves exportadores, não tiveram efeitos maiores para a economia regional. Aliás, há um nítido processo de re-primarização de sua economia. De acordo com os dados mais recentes das Contas Nacionais do IBGE, a indústria manufatureira perde relevância, permanecendo em torno de $5 \%$ da nacional, enquanto a extrativa dobra, saindo de 9,5\% (2002) para 18,5\% (2010), com destaque para o Pará, onde o avanço é excepcional, de $7 \%$ para $23 \%$, mas a indústria de transformação regride de $11,5 \%$ para $7 \%$ em igual período. A agricultura temporária como um todo (com destaque para soja e alimentos básicos, arroz, feijão e mandioca) também perde relevância, apesar do avanço crescente do agronegócio, mostrando que a decadência, ou melhor, o declínio da agricultura familiar, por ser superior à ascensão da produção de grãos, carvão vegetal e silvicultura, puxou o setor para baixo.

O posicionamento intrassetorial de algumas subatividades que compõem cada macroestrutura setorial permite distinguir adequadamente quais atividades são relevantes na economia regional. De acordo com os dados das Contas Nacionais, para 
2009, a distribuição estava assim configurada: na agropecuária, a dinâmica é dada pela agricultura temporária, pela silvicultura e pela exploração vegetal; na indústria, o destaque é dado pela construção civil e pela metalurgia; no setor de serviços e comércio, destacam-se as atividades vinculadas ao setor público (ADU) e aquelas voltadas para a prestação de serviços e comerciais.

\section{ESTRUTURA PRODUTIVA E OCUPAÇAO DA FORÇA DE TRABALHO}

A economia tradicional diz que a maior inserção de uma economia subdesenvolvida nos fluxos financeiros e de comércio (concretizada pela globalização) só traria vantagem por conta de fatores como: fluxo de capital, renda gerada, mudança tecnológica, emprego e divisa; ou seja, ocasionaria crescimento e desenvolvimento econômico. Os fatos ocorridos nas áreas periféricas do capital não confirmam essa hipótese. Os beneficiários foram poucos, e estão no andar de cima do capitalismo, formado por grandes grupos e segmentos específicos (os enclaves e quase enclaves) para as demais camadas (pequena e média empresa e a economia informal). Essa lógica neoliberal, que iguala segmentos diferentes, deixa-os paralisados ou Ihes aumenta o grau de vulnerabilidade, não funcionou adequadamente.

E essa repartição desigual de recursos e benefícios, que prevalece entre esses segmentos distintos, equedecorredaestratégiadedesenvolvimento atual, é que poderia explicar a estrutura e a dinâmica setorial do emprego dentro da economia. De um lado, milhões ocupados precariamente (agricultura e economia informal da indústria e serviços) ou, no linguajar economês, com baixa produtividade do trabalho; no outro, um número reduzido de empregos qualificados, alojados em áreas intensivas de capital (commodities) e de alta tecnologia (informática/ eletrônicos). Contrapondo a essa dicotomia, está a parte mais representativa do emprego formal originário do serviço público (municipal, estadual e federal): a do comércio e serviços.

A transição demográfica registrada nas últimas décadas alterou não apenas a taxa de crescimento e de participação da população urbana e rural sobre a total, mas também a queda de ocupação da população vinculada à agropecuária. Mesmo assim, o setor continua sendo o mais representativo de todos (mais de dois milhões), seguido do comércio e serviços de reparação, construção civil e serviços de educação, saúde e serviços sociais. Isso reflete o perfil da economia mostrado anteriormente, onde sobressaem o binômio grandes empresas capitalistas e unidades de fundo de quintal précapitalista. O setor industrial propriamente dito, isto é, o de manufatura, que só é importante no Estado do Amazonas (44\%) e no Pará (44\%), não foi dinâmico o suficiente para absorver o excedente gerado pela transição demográfica nas últimas décadas, nem muito menos a indústria extrativa e de monocultura, apesar do incremento absoluto e relativo que ocorreu nessas atividades. $O$ que se constata é que as mudanças setoriais ocorridas no período, na região, não foram capazes de alterar o padrão antigo de ocupação da força de trabalho, ou seja, quem efetivamente emprega são as atividades intensivas de mão de obra de baixa produtividade, espraiadas em todos os setores da indústria, agricultura, serviços e comércio.

\section{GRANDES PROJETOS E EXPROPIAÇAO TERRITORIAIS}

A presença do capital em determinada atividade e/ou região é função de um conjunto de variáveis, políticas, econômicas, e da geopolítica vigente no período, e historicamente esteve associada à ocupação e controle de mercado, mas em todas vem acompanhada de expropriação. A disputa por território deve ser vista como um processo em contínuo movimento, cuja resultante é produto da correlação de forcas que se efetiva entre as partes envolvidas, e, portanto, reflete o confronto instantâneo daquele momento, e, como tal, ele é instável, na medida em que, no momento seguinte, essa correlação de forças pode ser outra, resultando, assim, em um novo perfil para cada um dos envolvidos no ambiente em disputa (MESQUITA, 2011). Se, no nascimento do capitalismo, a disputa por território entre camponeses e criadores de ovinos foi a principal alavanca do processo de acumulação prévia, necessário e indispensável ao nascente capital industrial e base para formação e ampliação do mercado interno e de trabalho a essa fração do capital, contemporaneamente a entrada do capital no campo ou na cidade exerce função semelhante, ao expropriar velozmente, e também com o apoio do Estado, todos que estão na sua frente.

Na Amazônia, a expropriação decorrente dos incentivos fiscais, particularmente exercida pela pecuária, é muito conhecida, mas é apenas uma parte da questão; outros jogadores, inclusive mais importantes, estão também nesse time. Estamos nos referindo aos grandes projetos de investimento em diferentes atividades econômicas, liderados por grupos oligopólicos poderosos, muitos deles apoiados financeiramente pelo Estado. Podemos citar, como exemplos, empresas de diferentes ramos de atividades, como a Vale, a Albrás, a Suzano, a Cargill, a Alumar, a Bunge, a Petrobras e as superconstrutoras Camargo Correia, Andrade Gutierrez, que marcham em diferentes frentes, desorganizando e desarticulando populações rurais inteiras, estabelecidas secularmente, e que tinham nesses territórios seus espaços de sobrevivência e reprodução social. A especulação imobiliária, o cercamento de terras públicas, a invasão de áreas de preservação e parques nacionais tornam-se 
corriqueiros, assim como os conflitos sangrentos pelo seu controle. Esses espaços de milhões de hectares, antes livres e disponíveis a todos, passam a ter donos, viram campos de reprodução do capital, tornam-se mercadorias e/ou se tornam inviáveis, em função do uso que lhes é dado (represa área de preservação, parque nacional, área indígena). Para segmentos mais fragilizados, como os povos e comunidades tradicionais, essa ação deliberada do grande capital trouxe consequências desastrosas em termos de sobrevivência atual de perspectiva futura. Projetos como a Nova Cartografia Social da Amazônia têm radiografado esses confrontos, mostrando a sucessão de animosidades que prevalece entre esses empreendimentos, financiados com o dinheiro público e pequenos produtores familiares.

Apesar do sucesso alcançado por alguns desses megaempreendimentos, isso constitui a exceção. O resultado, em médio prazo, é a dispersão desses grupos sociais. A insegurança alimentar, a concentração de terra e renda e o aumento da desigualdade social, que decorrem do encolhimento de renda desses grupos, voltados para o extrativismo e a agricultura, os levarão a uma contínua reorganização produtiva (reprodutiva).

Como de praxe, deverão surgir, para os remanescentes (desses territórios), políticas compensatórias mediante a forma de novos programas e projetos especiais, no sentido de mitigar os problemas desse processo coletivo de expropriação fundiária em andamento na Amazônia sob a égide do Estado, a favor dos grandes projetos de investimento.

Embora o processo de expropriação fundiária efetivado contra pequenos produtores da Amazônia não seja fato recente, sem dúvida, no pós-1990, com a hegemonia das forças de mercado, ela se aprofunda e se generaliza, não deixando de fora nem os grupos mais tradicionais, como os ribeirinhos, os indígenas e os extrativistas, implicando um contínuo processo de territorialização e desterritorialização na Amazônia.

\section{CARÁTER INSTÁVEL E VULNERÁVEL DA ECONOMIA REGIONAL}

O perfil e o desempenho da economia regional (Amazônia) nas últimas décadas dão motivo para algumas reflexões. Apesar de o crescimento econômico ser maior do que o do país, isso não assegurou mudanças qualitativas significativas, traduzidas em um desenvolvimento econômico includente para a maioria da população. A razão estaria na estratégia de crescimento escolhida, já analisada anteriormente, e na manipulação da principal variável responsável por essa performance - o investimento -, efetivada pelos dois atores responsáveis - o Estado e os oligopólios -, e também no vínculo forte da demanda externa. O investimento, que é a variável determinante da economia, é quem define o caráter da instabilidade do crescimento, pois depende de um conjunto complexo de elementos, sendo a eficiência marginal do capital (expectativa de retorno) o principal deles. (KEYNES, obra não citada nas Referências 1987). O investimento pode ser público e privado. Sobre o primeiro, o governo poderia interferir diretamente; sobre o segundo (também sobre a demanda externa), via uma política econômica que induza a iniciativa privada a fazê-lo. A questão é como atuar sobre essa variável numa situação onde a presença do Estado na economia é demonizada, como era durante o período neoliberal. Não fará. É o mercado que fará isso, e, como tal, fará à sua maneira, isto é, em atividades e regiões específicas, não necessariamente aquelas que precisam de investimentos. A presença do investimento público torna-se secundária. Só com a reformulação do papel do Estado no último governo Lula é que o investimento público na região volta a ter relevância.

Por outro lado, como o crescimento regional depende em parte da demanda externa, dada a importância das commodities nesse período, ele assume também o caráter vulnerável. Ou seja, o crescimento regional é refém dos investimentos públicos e da demanda externa, da exportação de commodities, de modo que é a partir do seu crescimento que se operacionaliza a decisão de investir.

\section{CONCLUSÃO}

Considerando que a estratégia atual de desenvolvimento é a mesma da década de 1980, baseada em enclaves, na demanda externa e na dependência do investimento público, e que não há uma proposta alternativa de desenvolvimento, a tendência desse perfil atual (de concentração e apropriação da riqueza e de desigualdade de renda) é aprofundar os problemas nas esferas ambiental, social eeconômica. Como se sabe, o desenvolvimento capitalista é por natureza desigual e excludente, e, portanto, não se espere que as distorções sejam corrigidas nesse processo. A responsabilidade é da sociedade. A questão é como substituir o padrão de desenvolvimento por outro, num cenário dominado pelo individualismo, pela conjuntura imposta pela política neoliberal, que, apesar da crise de 2008, continua hegemônica, impondo seu modus operandi via política macroeconômica ortodoxa aqui e alhures.

\section{REFERÊNCIAS}

BRAUDEL, Fernand. The structures of everyday life. New York: Harper \& Rom, 1981.

INSTITUTO BRASILEIRO DE GEOGRAFIA E ESTATÍSTICAS. Censos agropecuários do 
Maranhão. Rio de Janeiro, 1970

. Censos agropecuários do Maranhão. Rio

de Janeiro, 1995-1996.

Censos agropecuários do Maranhão. Rio de Janeiro, 2006.

Contas regionais do Brasil (2002-2010). Rio de Janeiro, 2013.

Sistema IBGE de Recuperação Automática-Sidra. Rio de Janeiro, 2013. Disponível em: http://www.sidra.ibge.gov.br/bda/territorio/carto. asp?func $=\mathrm{imp} \& \mathrm{z}=\mathrm{t} \& \mathrm{o}=10 \& \mathrm{i}=\mathrm{P}>$. Acesso em: $1 \mathrm{abr}$. 2013.

MESQUITA. B. A política neoliberal e o impacto na expansão do agronegócio na Amazônia Brasileira. In: COLÓQUIO INTERNACIONAL DE LA SEPLA, 4., 2008, Buenos Aires. Anais... Buenos Aires: [s. n.], 2008.

0 desenvolvimento desigual da agricultura: a dinâmica do agronegócio e da agricultura familiar. São Luís: Edufma, 2011.

. Demanda por alimentos e as consequências na Amazônia brasileira: "sucesso" do agronegócio e tragédia do desmatamento. In: ENCUENTRO DE GEÓGRAFOS DE AMÉRICA LATINA, 12., 2009, Montevidéu. Anais... Montevidéu, 2009.

NOTA

1 Trata-se a presente reflexão de um roteiro, uma proposta esquemática para examinar algumas questões pertinentes à Mesa Temática Coordenada "Desenvolvimento e grandes projetos na Amazônia: desigualdade e concentração de riqueza"; desenvolvida no âmbito da VI Jornada Internacional de Políticas Públicas (VI Joinpp) com outros pesquisadores convidados: José de Ribamar Sá Silva (UFMA), Alfredo Wagner de Almeida (UFAM) e Gérson Teixeira Mendes (ABRA).

\section{Benjamin Alvino de Mesquita}

Economista.

Doutor em Políticas Públicas pelo Programa de PósGraduação em Políticas Públicas da Universidade Federal do maranhão (UFMA)

Professor da Universidade Federal do Maranhão (UFMA)

E-mail: bamin@elo.com.br

\section{Universidade Federal do Maranhão - UFMA}

Cidade Universitária, Av, dos Portugueses, 1966

Bacanga - São Luís/Ma

CEP: $65.085-580$ 